\title{
Occurrence of Salmonella Typhimurium resistance under sublethal/repeated exposure to cauliflower infusion and Infection effects on Caernohabditis elegans host test organism
}

Maria Sanz-Puig ${ }^{\mathrm{a}}$, Alejandra Arana-Lozano ${ }^{\mathrm{a}}$, M. Consuelo Pina-Pérez ${ }^{\mathrm{b}}$, Pablo Fernandez ${ }^{\mathrm{c}}$, Antonio Martinez ${ }^{\mathrm{a}}$, Dolores Rodrigo ${ }^{\mathrm{a}^{*}}$

a Instituto de Agroquímica y Tecnología de Alimentos - Consejo Superior de Investigaciones Científicas (IATA-CSIC). Unidad Asociada UPCT. Paterna, València, Spain.

${ }^{\mathrm{b}}$ Institute of Life Technologies, HES.SO VALAIS-WALLIS, Route du Rawil 64, Sion, Switzerland

${ }^{\mathrm{c}}$ Universidad Politécnica de Cartagena. Unidad Asociada al CSIC. Cartagena, Murcia, Spain.

"corresponding author:lolesra@iata.csic.es

\section{Abstract}

Resistant bacteria to antimicrobials are increasingly emerging in medical, food industry and livestock environments. The present research work assesses the capability of Salmonella enterica var Typhimurium to become adapted under the exposure to a natural cauliflower antimicrobial by-product infusion in consecutive repeated exposure cycles. Caernohabditis elegans was proposed as in vivo host-test organism to compare possible changes in the virulent pattern of the different rounds treated S. enterica var Typhimurium and untreated bacterial cells.

According to the obtained results, S. enterica var Typhimurium was able to generate resistance against a repeated exposure to cauliflower by-product infusion $5 \%(w / v)$, increasing the resistance with the number of exposed repetitions. Meanwhile at the first exposure, cauliflower by-product infusion was effective reducing $S$. enterica var Typhimurium $\left(\approx 1 \log _{10}\right.$ cycle), S. enterica var Typhimurium become resistant to this natural antimicrobial after the second and third treatment-round, and was able to grow $\left(\approx 1 \log _{10}\right.$ cycle). In spite of the increased resistance observed for repeatedly treated bacteria, the present study reveals no changes on $C$. elegans infection effects between resistant and untreated $S$. enterica var Typhimurium, according to phenotypic parameters evaluation (lifespan duration and egglaying). 
31 Keywords: Natural antimicrobials, S. enterica var Typhimurium, resistance, Caernohabditis 32 elegans, infection.

\section{Introduction}

Hurdle technology is a processing concept industrially well established to achieve efficient microorganisms reduction by the combination of different preservation techniques applied at slight intensive conditions maintaining natural valuable properties of foods treated products from a nutritional and sensory point of view (Pasha et al., 2014; Pina-Pérez et al., 2013; SanzPuig et al., 2017a). The combination of natural or chemical antimicrobials with other physical methods is one of the most commonly used practices to synergistically enhance microbial and enzymes reduction improving the safety and shelf-life of treated products (Guerrero et al., 2017; Sudhaus et al., 2012). However, nowadays, consumers are really concerned about chemical additives, many of them close related with allergies and other possible health problems (Asioli et al., 2017). Natural antimicrobials (e.g. polyphenols, glucosinolates, vegetable pigments, antimicrobial peptides) and phytochemical extracts (from soya, Stevia Rebaudiana Bertoni, cauliflower infusion, citrus fruits essential oils extracts) could be introduce in food formulation as an alternative to synthetic antimicrobials (Gutierrez et al., 2009; Sansano et al., 2017; Sanz-Puig et al., 2015a; Tiwari et al., 2009), additionally with other technological (thickening agents, gelling agents) and functional effects in novel food (enhanced 
antioxidant potential, enhanced fiber content in food). Many bioactive compounds can be obtained from agro-industrial by-products (Fernandez-Lopez et al., 2005; Sanz-Puig et al., 2015 a,b; Viuda-Martos et al., 2007). Sanz-Puig et al. (2015b) studied different concentrations of vegetable by-product infusions (cauliflower, mandarin, orange, lemon, and okara) against Salmonella enterica var Typhimurium, and according to the obtained results $5 \%(\mathrm{w} / \mathrm{v})$ of cauliflower resulted the most effective bactericidal natural aqueous extract reducing close to 6 $\log _{10}$ cycles the initial S. enterica var Typhimurium load. Valorization studies carried out to make profit from valuable vegetable wastes from food industry is in the priority research axes of the European Union H2O20 in order to support sustainable development by means of circular economy fundamentals (EC, 2017).

Microorganisms are becoming adapted and resistant to (i) veterinary antibiotics, used in animals farming, (ii) clinical antibiotics used in human medicine and (iii) antimicrobial additives used in food preservation, representing a great concern for the scientific community (WHO, 2017).

Cross-resistances along the complete food chain, and changes in virulence of pathogenic bacteria, may even emerge (Kalily et al., 2016, 2017; Kisluk et al., 2013). Zanini et al. (2014) studied the bacterial adaptive responses to antibiotics induced by sublethal concentration of citral on first- and second-generation cells of Listeria monocytogenes serovar $4 \mathrm{~b}$ and Salmonella enterica var Typhimurium. They concluded that the presence of citral in the culture medium of L. monocytogenes $4 \mathrm{~b}$ and $S$. enterica var Typhimurium increased the antibiotic susceptibility of the first generations, while an increase in antibiotic resistance was observed in the second generation of S. enterica var Typhimurium.

Recent in vivo models are being proposed to evaluate mechanisms of pathogenic infection, and bacterial genes responsible for changes in virulence. Among those, Additionally, C. elegans has been defined as a valid model for human pathogen infection, disease and health 
promotion (Balla and Troemel, 2013; Gammon, 2017; Kurz and Ewbank, 2000). The evaluation of the $C$. elegans lifespan has been previously used as an indicator of the impact that certain molecules, e.g. antioxidants, metabolites and synthetic compounds, could have on human health and their influence in the anti-aging process (Liu et al., 2016; Rollins et al., 2017; Wang and Wink, 2016).

Silva et al. (2015) evaluated the effect of two antimicrobial substances, carvacrol and citral, on L. monocytogenes and $L$. innocua cells, as well as possible virulence changes in sub-lethally damaged cells, using C. elegans as in vivo test organism. According to Silva et al. (2015) results, the lifespan of $C$. elegans population fed on a lawn of L. monocytogenes previously treated with carvacrol was reduced in comparison with lifespan exerted by C. elegans population fed on a lawn of E. coli OP50 (as negative control), L. monocytogenes treated with citral, and, treated/not treated L. innocua.

Understanding the behaviour of foodborne pathogens exposed to sublethal concentrations of natural antimicrobials, and the possible implications in terms of bacterial resistance generation and changes in virulence are key questions to search for alternatives to conventional preservatives in food and to assess the safety of the hurdle technology processing application (Pina-Perez et al., 2013; Sanz-Puig et al., 2017a). Evaluation of some C. elegans phenotypic factors (such as lifespan, reproduction patterns, and mobility) under the exposure to pathogenic human bacteria could be a preliminary indicator of risks for consumers when these natural antimicrobials are used below the bactericidal dosage for food formulation with preservative objectives (Kastbjerg et al., 2010; Schroeder et al., 2017).

The main aim of the present study is the assessment of $S$. enterica var Typhimurium behaviour under the repeatedly exposure to a cauliflower natural antimicrobial extract, subsequently evaluating the effects of infection by repeatedly treated/untreated $S$. enterica var Typhimurium on the $C$. elegans in vivo host-model organism. 


\subsection{Cauliflower by-product extract}

108

Cauliflower by-product (mainly external leaves of cauliflower plants) was provided as dehydrated residues from primary production of TRASA S.L., and was washed in sterile water, dried and homogenized using a laboratory grinder (Janke \& Kunkel IKA Labortechnik) (Brandi et al., 2006).

Five per cent $(\mathrm{w} / \mathrm{v})$ of dried cauliflower by-product was selected in the previous study according to previous results of Sanz-Puig et al. (2015a). The infusion was prepared as follows: buffered peptone water $(0.1 \%(\mathrm{w} / \mathrm{v}))$ was boiled and then the dry by-product was added and allowed to infuse for $30 \mathrm{~min}$ (Sanz-Puig et al., 2016). The extracts were then centrifuged at 4,000 rpm for $15 \mathrm{~min}$ at $4{ }^{\circ} \mathrm{C}$ and filtered three times, using filters with a pore size of 11 and $2.5 \mu \mathrm{m}$ to eliminate smaller particles (Whatman), and $0.45 \mu \mathrm{m}$ (PVDF syringe filter) to sterilize.

\subsection{Bacterial strain}

A pure culture of $S$. enterica var Typhimurium (CECT 443) was provided freeze-dried by the Spanish Type Culture Collection. It was rehydrated with $10 \mathrm{~mL}$ of tryptic soy broth (TSB) (Scharlab Chemie, Barcelona, Spain). After $20 \mathrm{~min}$, it was transferred to $500 \mathrm{~mL}$ of TSB and incubated at $37^{\circ} \mathrm{C}$ with continuous shaking (Selecta Unitronic) at $200 \mathrm{rpm}$ for $14 \mathrm{~h}$ to obtain cells in a stationary growth stage. The cells were centrifuged (Beckman Avanti J-25) twice at $4.000 \mathrm{rpm}$ and at $4{ }^{\circ} \mathrm{C}$ for $15 \mathrm{~min}$ and then resuspended in TSB. The cells were finally resuspended in $20 \mathrm{~mL}$ of TSB, then dispensed in $2 \mathrm{~mL}$ vials with glycerol at $20 \%$ to a final concentration of $10^{8} \mathrm{CFU} / \mathrm{mL}$ obtained by plate count, and finally frozen and stored at $-80{ }^{\circ} \mathrm{C}$. 
131 The initial population of $S$. enterica var Typhimurium $\left(10^{7} \mathrm{CFU} / \mathrm{mL}\right)$ was exposed to three

132 consecutive antimicrobial treatments. Each treatment consisted in exposure to $5 \%(\mathrm{w} / \mathrm{v})$ 133 cauliflower by-product infusion at $37^{\circ} \mathrm{C}$ for $4 \mathrm{~h}$ with continuous shaking (200 rpm) (sub-lethal 134 treatment) (Sanz-Puig et al., 2015a). Afterwards, the sample was centrifuged to recover the 135 microbial cells. Recovered cells were grown in TSB culture overnight to achieve stationary 136 phase $\left(10^{9} \mathrm{CFU} / \mathrm{mL}\right)$, inoculated in cauliflower by-product extract $\left(10^{7} \mathrm{CFU} / \mathrm{mL}\right)$ and treated 137 again using the same conditions as described above. Before and after each treatment, the antimicrobial effect against the S. enterica var Typhimurium population was evaluated by plate count in tryptic soy agar (TSA) (Scharlab Chemie, Barcelona, Spain). The entire experiment was carried out in triplicate with three different infusion batches.

S. Typhimurium treated once and S. enterica var Typhimurium treated three times were included in the $C$. elegans infection study, because they were the most different populations with regard to their resistance to the cauliflower antimicrobial exposure.

\subsection{C. elegans studies}

C. elegans strain N2, obtained from the College of Biological Sciences, Minnesota University, USA, was used to evaluate the possible virulence changes in S. enterica var Typhimurium populations as a consequence of repeated exposure to antimicrobial from cauliflower byproduct infusion. C. elegans was maintained in plates with Nematode Growth Medium (NGM) agar and a bacterial lawn of E. coli OP50 (Silva et al., 2015). In order to evaluate the effect of different S. enterica var Typhimurium subpopulations on the survival of C. elegans, 5 repetitions of 50 synchronized young adult nematodes ( 250 in total), distributed in 5 plates of 10 worms each, were transferred to NGM agar with a lawn of untreated S. enterica var Typhimurium (control) $\left(10^{7} \mathrm{CFU} /\right.$ per plate). This was repeated for 
treated S. enterica var Typhimurium populations (Salmonella treated once and treated three times with cauliflower by-product extract) $\left(10^{7} \mathrm{CFU} /\right.$ per plate). The worms were maintained at $20^{\circ} \mathrm{C}$ during their life cycle (approximately three weeks) and were examined at $48 \mathrm{~h}$ intervals. Worms were considered dead when they did not move and did not respond to stimulation (contact with a platinum worm picker).

The effect of selected S. enterica var Typhimurium populations on egg laying of $C$. elegans was also assessed. For this purpose, 10 worms were transferred to NGM plates with a lawn of untreated $S$. Typhimurium or $S$. Typhimurium treated with antimicrobial by-product extract, and the number of eggs laid was counted at $48 \mathrm{~h}$ intervals.

\subsection{Statistical analysis of data}

An ANOVA analysis was carried out to detect significant differences ( $p$-value $\leq 0.05$ ) between microbial resistance under the exposure to cauliflower by-product infusion, and phenotypic differences in C. elegans infection due to different bacterial populations. Additionally, survival data for C. elegans were analysed by using the Kaplan-Meier method, and the hazard function and percentiles of estimated survival distribution were obtained. All statistical analyses were performed using Statgraphics Centurion XII software (Statpoint Technologies, Inc., Warrenton, VA, USA).

\section{Results}

Figure 1 shows the microbial inactivation and growth ( $\log _{10}$ cycles) of the initial S. enterica var Typhimurium population $\left(10^{7} \mathrm{CFU} / \mathrm{mL}\right)$ caused by each cauliflower by-product infusion treatment round. As can be seen graphically, $1.04 \log _{10}$ cycles of inactivation were achieved after the first cauliflower by-product exposure. However, subsequently exposed cells were 
resistant to the antimicrobial cauliflower effect, and even able to grow $\left(\approx 1 \log _{10}\right.$ cycle after the third exposure).

In a second step, $C$. elegans was used as a host-model organism for infection, fed with $S$. enterica var Typhimurium: untreated (control), treated once (sensitive to cauliflower effect), and treated three times (resistant to cauliflower bactericidal effect and able to grow). Lifespan, movement, and egg-laying were phenotypic factors under study to evidence possible changes in bacterial virulence between untreated and different populations of resistant treated $S$. enterica var Typhimurium bacteria.

Figure 2 shows the percentage of surviving nematodes during their life cycle, when they were fed with (i) untreated S. enterica var Typhimurium, (ii) treated once, and (iii) treated three times with cauliflower by-product infusion. The C. elegans survival curve indicated that during their life cycle (until day 18 ) the number of living nematodes was higher ( $p$-value $<0.05$ ) for $C$. elegans fed with treated S. enterica var Typhimurium (one or three times) than for C. elegans fed with untreated S. enterica var Typhimurium. Owing to the life cycle of the worm, the number of nematodes decreased with time; but, survival was up to 21 days for worms fed with untreated S. enterica var Typhimurium, and 23 and 25 days for nematodes fed with S. enterica var Typhimurium treated once and three times, respectively. Nevertheless, non-significant differences were found between survival data of nematode populations fed with $S$. enterica var Typhimurium treated once and three times ( $p$-value $>0.05$ ).

Survival data were analysed by using a Kaplan-Meier method to obtain the hazard function for different $C$. elegans individuals fed with different S. Typhimurium subpopulations (see Figure 3) and percentiles (Table 1). As can be seen in the figure 3, the hazard was always higher when the nematodes were fed with untreated S. Typhimurium than when they were fed with treated S. enterica var Typhimurium. From day 14 onwards, the hazard increased more slowly 
for $C$. elegans fed with S. enterica var Typhimurium treated once and three times than for $C$. elegans fed with untreated S. enterica var Typhimurium.

207 Also the percentiles of estimated survival distribution were obtained. Table 1 shows percentiles of estimated survival distribution for each of the $C$. elegans populations. If we focus on the $5 \%$ percentile (percentage of worms surviving for a given time), it can be seen that there are significant differences $(p$-value $<0.05)$ between $C$. elegans fed with treated $S$. enterica var Typhimurium (treated once: 19.3 days, and three times: 19.9 days) and untreated S. Typhimurium (16.5 days).

Egg lying was also studied as a complementary test. In optimal conditions, C. elegans lays about 300-350 eggs during its life cycle (approximately 21 days) (Labrousse et al., 2000). However, when the nematodes were fed and infected with any of the subpopulations of $S$. enterica var Typhimurium considered in this study, egg-laying was only maintained until the $5^{\text {th }}$ day. Figure 4 shows a comparison of the number of eggs laid by $C$. elegans fed with the three different S. enterica var Typhimurium subpopulations for two periods of time (from 0 to 2 days and from 2 to 4 days). In the first period of time ( 0 to 2 days) significant differences ( $p$-value $<$ 0.05 ) were found in the number of eggs laid by nematodes fed with the three $S$. Typhimurium subpopulations. Nematodes fed with untreated S. enterica var Typhimurium laid fewer eggs than nematodes fed with S. enterica var Typhimurium treated once. The highest number eggs laid in the first period are corresponding with nematodes fed with S. enterica var Typhimurium treated three times. For the second time period ( 2 to 4 days) the number of eggs laid by the worms was almost the same in all cases, and lower than the number of eggs laid in the first period of time. These results are important because, despite the effect of $S$. enterica var Typhimurium on the egg-laying rate during the life cycle of the nematode, it appears that $S$. enterica var Typhimurium treated with the cauliflower by-product extract was less virulent in 
relation to egg laying than the untreated Salmonella, thus corroborating the findings observed

231 in the survival data and the Kaplan-Meier analysis.

\section{Discussion}

Antimicrobial resistance and adaptation is mediated by specific genes encoded for bacterial protection or generally due to spontaneous mutations in the bacterial chromosome. Once the development of resistance has occurred, the mutated gene is directly transferred to the bacteria's progeny during replication (Tiwari and Tiwari, 2011). The results of this study are revealing the capability of $S$. Typhimurium to develop microbial resistance/adaptation to cauliflower by-product infusion after being exposed to consecutive sub-lethal treatments that inactivated only part of the initial microbial population. Various authors (Di Pasqua et al., 2006; Ultee et al., 2000) have shown specific adaptation of E. coli, S. Senftenberg, S. Typhimurium and Bacillus cereus to sublethal concentrations of essential oils. Kalily et al. (2016) found linalool-resistant mutants of $S$. Senftenberg. Development of resistance to these natural antimicrobial has been associated to structural and functional changes in microbial cells, specifically in their cell membranes (Ali et al., 2018; Kalily et al., 2016; McMahon et al., 2007). Recent scientific studies have also demonstrated development of microbial resistance of $S$. enterica var Typhimurium to several antibiotics such as cephalosporins or fluoroquinolones or cross-protection against antibiotics (Kalily et al., 2017; Kariuki et al., 2015; Zanini et al., 2014). Additional studies are also demonstrated the development of resistance when S. enterica var Typhimurium is treated with non-essential oil natural antimicrobials (polyphenols) (Gupta and Birdi, 2017). Under other sub-lethal physical treatments, like Pulsed Electric Fields and High Hydrostatic Pressure, S. enterica var Typhimurium has also demonstrated ability to be adapted (Sanz-Puig et al., 2018)

In order to further understand the mechanism of resistant bacteria infection, and the possible evident changes in virulence due to this adaptation step in relation to untreated bacteria, the 

in the C. elegans infection model (Battisti et al., 2017). The rapid growth and short generation time of $C$. elegans permit extensive screens for pathogens infective potential, some of the factors identified in these screens have also been shown to play roles in mammalian infections. In the present study, C. elegans was fed with different populations, untreated S. enterica var Typhimurium and cauliflower treated bacteria, once and three times, the last one highly resistant to the natural cauliflower antimicrobial exposure. Firstly, the nematode intestinal epithelium should recognize and respond to pathogens in a microbe-specific manner. According to several previous reported studies, the accumulation of the bacteria in the intestine is traduced in several pathologies in C. elegans. The survival of $C$. elegans is dependent on the type and availability of bacteria on which to feed, among other factors (Allen et al., 2015). Although some studies have indicated that the lifespan of worms fed with S. enterica var Typhimurium decreased significantly (Aballay et al., 2000; Labrousse et al., 2000), neither of those studies contemplated infecting the worms with naturally occurring resistant subpopulations of S. enterica var Typhimurium, repeatedly exposed to natural cauliflower infusion. According to results, it seems that the lifespan of worms fed with treated S. enterica var Typhimurium was longer than the lifespan of worms fed with untreated Salmonella. This behaviour indicating that resistant S. enterica var Typhimurium are not more virulent for C. elegans than untreated type. Ahmed et al. (2016) identify the antimicrobialresistance genes in Salmonella Typhimurium to be mainly blaTEM and floR, detected at frequencies 53 and $73 \%$ respectively in Salmonella isolated from chicken meat. Wild types of Salmonella are specifically capable to produce enterotoxins controlled by the expression of a series of virulence-genes such as stn (Barilli et al., 2018). Antimicrobial exposure can modulate the virulence of S. enterica var Typhimurium. In that sense, several reports are supporting the capability of bacteria (Mycobacterium, Escherichia coli, Salmonella enterica, Pseudomonas aeruginosa) to acquire de novo resistance under inadequate treatment regimes (Schroeder et 

inactivation, changes in the antimicrobial target, changes in cell permeability) is another of the possible explanations for these increased survival of $S$. enterica var typhimurium under the repetitive exposure to cauliflower infusion (Brooks and Brooks, 2014; Sanz-Puig et al., 2017b, 2018). In the present study, cauliflower resistant S. enterica var Typhimurium seems to be less virulent for the fed nematode than untreated one.

The increase in the hazard from day 14 is probably related with the age of the nematodes, which are already considered old at that time, and with their immunity system, which is less efficient than in younger nematodes and consequently more sensitive to infection under virulent subpopulations of S. enterica var Typhimurium. Thomas et al. (2004) also found that the rate at which wild-type $C$. elegans was killed by the bacterial pathogens tested (S. enterica var Typhimurium, among others) increased as nematodes aged, irrespective of the precise mechanism of killing. Similar results were also found by Kurz et al. (2003) in nematodes infected with Serratia marcescens.

With regard to egg laying, egg-laying events tend to be clustered in short bursts, or active phases, which are separated by longer inactive phases during which eggs are retained (Hart et al., 2006). Reproductive function begins on about day 5 of adulthood, and reproduction ceases after 10-14 days of adulthood (Christopher and Kerry, 2013). Results of the present study indicated that $S$. enterica var Typhimurium treated once and three times and untreated $S$. Typhimurium modified the laying pattern of the worms. For all studied scenarios for infection, egg laying stopped on the $5^{\text {th }}$ day after contact with the pathogen. Previous research studies have indicated that live cells of $S$. Typhimurium are accumulated in the lumen of the intestine of $C$. elegans, that becomes completely infected by the $5^{\text {th }}$ day of contact with this bacterium (Aballay et al., 2000; Gardner et al., 2013; Labrousse et al., 2000). Other previous studies have also registered the $C$. elegans egg-laying pattern as indicator of microbial virulence, showing 
308 the number of eggs retained related with the virulence of E. faecalis strain used in each case

309 (Gardner et al., 2013). This retention of progeny observed in the present study is 310 corresponding in time with the progressive accumulation of S. enterica var Typhimurium in the

311 lumen of the nematode. Additionally, other research studies have demonstrated that $S$.

312 Typhimurium infection can affect $C$. elegans egg laying and the eggs hatch internally, which

313 contributes significantly to killing the worms in the first days of their lifespan (Garden et al.,

314 2013; Labrousse et al., 2000). In spite of the fact that egg laying stopped on the $5^{\text {th }}$ day in all

315 cases, higher number of eggs was detected for $C$. elegans fed with resistant bacteria in

316 comparison with egg laying pattern of C. elegans fed with untreated S. Typhimurium.

317 In the present study, the survival data, the Kaplan-Meier analysis and the egg-laying behaviour

318 used to assess the effect of infection by resistant bacteria on $C$. elegans revealed that an 319 increase in resistance does not mean that microorganisms become more virulent for $C$. 320 elegans, although S. enterica var Typhimurium still maintains some level of virulence, as can be 321 deduced from the egg-laying study. Complex relationship between antimicrobial resistance 322 and virulence genes involved in each specific treatment process should be elucidated in order 323 to develop safest processes and products. 
327 The present research work provides valuable information regarding the resistance

328 development of S. enterica var Typhimurium under the repeated exposure to a natural

329 antimicrobial obtained from the agri-food by-products. Valorization of natural compounds

330 from vegetables, and the development of novel ingredients is feasible and demanded by

331 industry and consumers. Potential functionalities can appear related to creation of more

332 convenient, healthy and minimally processed products. However, associated risks should be

333 accurately predicted. No virulence increment by the exposure to cauliflower infusion was

334 detected in the present study using one of the most concerning foodborne pathogens using an

335 in vivo test-organism C. elegans.

336

\section{Conflict of interest}

338 The authors declare that there is no conflict of interests regarding the publication of this 339 paper.

340 
Aballay A, Yorgey P and Ausubel FM (2000) Salmonella Typhimurium proliferates and establishes a persistent infection in the intestine of Caenorhabditis elegans. Current Biology 10: 1539-1542.

Allen EN, Ren J, Zhang Y and Alcedo J (2015) Sensory systems: Their impact on C. elegans survival. Neuroscience $296: 15-25$.

Ali J, Rafiq QA and Ratcliffe E (2018). Antimicrobial resistance mechanisms and potential synthetic treatments. Future Science OA 4(4): 1-10.

Asioli D, Aschemann-Witzel J, Caputo V, Vecchio R, Annunziata A, Næs T and Varela P (2017) Future Science OAMaking sense of the "clean label" trends: A review of consumer food choice behavior and discussion of industry implications. Food Research International 99(1): 58-71.

Balla KM and Troemel ER (2013) Caenorhabditis elegans as a model for intracellular pathogen infection. Cell Microbiology 15(8): 1313-1322.

Barilli E, Bacci C, Stella Villa Z, Merialdi G, D'Incau M, Brindani F and Vismarra A (2018) Antimicrobial resistance, biofilm synthesis and virulence genes in Salmonella isolated from pigs bred on intensive farms. Italian Journal of Food Safety 3, 7(2): 1-7.

Battisti JM, Watson LA, Naung MT, Drobish AM, Voronina E and Minnick MF (2017) Analysis of the Caenorhabditis elegans innate immune response to Coxiella burnetii. Innate Immunology 23(2): 111-127.

Brandi G, Amagliani G, Schiavano GF, de Santi M and Sisti M (2006) Activity of Brassica oleracea leaf juice on foodborne pathogenic bacteria. Journal of Food Protection 69: 22742279.

Brooks BD and Brooks AE (2014) Therapeutic strategies to combat antibiotic resistance. Advanced Drug Delivery Reviews 30: 78, 14-27.

Christopher LP and Kerry K (2013) Age-related degeneration of the egg-laying system promotes matricidal hatching in Caenorhabditis elegans. Aging Cell 12: 544-553.

Di Pasqua R, Hoskins N, Betts G and Mauriello G (2006). Changes in membrane fatty acids composition of microbial cells induced by addiction of thymol, carvacrol, limonene, cinnamaldehyde, and eugenol in the growing media. Journal of Agricultural and Food Chemistry 547: 2745-2749.

European Commission (EC). 2017. Implementation of the circular economy action Plan. Available at: http://ec.europa.eu/environment/circular-economy/index_en.htm 
Fernandez-Lopez J, Zhi N, Aleson-Carbonell L, Perez-Alvarez JA and Kuri V (2005). Antioxidant and antibacterial activities of natural extracts: application in beef meatballs. Meat Science 69: 371-380.

Gammon DB (2017) Caenorhabditis elegans as an Emerging Model for Virus-Host Interactions. Journal of Virology 1-7.

Gardner M, Rosell M, Myers EM (2013). Measuring the Effects of Bacteria on C. elegans Behaviour Using an Egg Retention Assay. Journal of Visualized Experiment 80: 1-6.

Guerrero SN, Ferrario M, Schenk M and Carrillo MG (2017). Chapter 3 - Hurdle Technology Using Ultrasound for Food Preservation. Bermudez-Aguirre D (eds) Ultrasound: Advances for Food Processing and Preservation. Cambridge: Elsevier Academic Press, pp: 39-99

Gupta PD and Birdi TJ (2017). Development of botanicals to combat antibiotic resistance. Journal of Ayurveda and Integrative Medicine 8(4): 266-275.

Gutierrez J, Barry-Ryan C and Bourke P (2009). Antimicrobial activity of plant essential oils using food model media: efficacy, synergistic potential and interactions with food components. Food Microbiology 26: 142-150.

Hart AC (2006). Behavior. Hart AC (eds) The C. elegans Research Community. Pasadena (CA): WormBook, pp: 1-67.

Kalily E, Hollander A, Korin B, Cymerman I and Yaron S (2016) Mechanisms of resistance to linalool in Salmonella Senftenberg and their role in survival on basil. Environmental Microbiology 18(11): 3673-3688.

Kalily E, Hollander A, Korin B, Cymerman I and Yaron S (2017) Salmonella Senftenberg adaptation to linalool and its association with antibiotic resistance and environmental persistence. Applied and Environmental Microbiology 1-17.

Kariuki S, Gordon MA, Feasey N and Parry CM (2015) Antimicrobial resistance and management of invasive Salmonella disease. Vaccine 33(3): 21-29.

Kastbjerg VG, Larsen MH, Gram L and Ingmer H (2010) Influence of Sublethal Concentrations of Common Disinfectants on Expression of Virulence Genes in Listeria monocytogenes. Applied and Environmental Microbiology 76(1): 303-309.

Kisluk G, Kalily E and Yaron S (2013) Resistance to essential oils affects survival of Salmonella enterica serovars in growing and harvested basil. Environmental Microbiology 15: 2787-2798.

Kurz CL, Chauvet S, Andres E, Aurouze M, Vallet I, Michel GP, Uh M, Celli J, Filloux A, De Bentzmann S, Steinmetz I, Hoffmann JA, Finlay BB, Gorvel JP, Ferrandon D and Ewbank JJ 
(2003) Virulence factors of the human opportunistic pathogen Serratia marcescens identified by in vivo screening. EMBO Journal 22: 1451-1460.

Kurz CL and Ewbank JJ (2000) Caenorhabditis elegans for the study of host-pathogen interactions. Trends in Microbiology 8(3): 142-144.

Labrousse A, Chauvet S, Couillault C, Kurz CL and Ewbank JJ (2000) Caenorhabditis elegans is a model host for Salmonella Typhimurium. Current Biology 10: 1543-1545.

Liu H, Guo M, Xue T, Guan J, Luo L and Zhuang Z (2016) Screening lifespan-extending drugs in Caenorhabditis elegans via label propagation on drug-protein networks. BMC Systems Biology series 10(4): 1-11.

McMahon MAS, Xu J, Moore JE, Blair IS and McDowell DA (2007) Environmental Stress and Antibiotic Resistance in Food-Related Pathogens. Applied and Environmental Microbiology 73(1): 211-217.

Pasha I, Saeed F, Sultan MT, Khan MR and Rohi M (2014) Recent developments in minimal processing: a tool to retain nutritional quality of food. Critical Reviews in Food Science and Nutrition 54: 340-351.

Pina-Pérez MC, Martínez-López A and Rodrigo D (2013) Cocoa powder as a natural ingredient revealing an enhancing effect to inactivate Cronobacter sakazakii cells treated by Pulsed Electric Fields in infant milk formula. Food Control 32(1): 87-92.

Rollins JA, Howard AC, Dobbins SK, Washburn EH and Rogers AN (2017) Assessing Health Span in Caenorhabditis elegans: Lessons From Short-Lived Mutants. Journal of Gerontology: A Biological Sciences and Medical Sciences 1 72(4): 473-480.

Sansano S, Rivas A, Pina-Pérez MC, Martinez A and Rodrigo D (2017) Stevia rebaudiana Bertoni effect on the hemolytic potential of Listeria monocytogenes. International Journal of Food Microbiology 5(250): 7-11.

Sanz-Puig M, Pina-Pérez MC, Criado MN, Rodrigo D and Martínez-López A (2015a). Antimicrobial potential of cauliflower, broccoli, and okara byproducts against foodborne bacteria. Foodborne Pathogens and Diseases 12(1): 39-46.

Sanz-Puig M, Pina-Pérez MC, Rodrigo D and Martínez-López A (2015b) Antimicrobial activity of cauliflower (Brassica oleracea var. Botrytis) by-product against Listeria monocytogenes. Food Control 50: 435-440.

Sanz-Puig M, Santos-Carvalho L, Cunha LM, Pina-Pérez MC, Martínez A and Rodrigo D (2016) Effect of pulsed electric fields (PEF) combined with natural antimicrobial by-products against $S$. Typhimurium. Innovative Food Science and Emerging Technologies 37: 322-328. 
Sanz-Puig M, Moreno P, Pina-Pérez MC, Rodrigo D and Martínez A (2017a) Combined effect of high hydrostatic pressure (HHP) and antimicrobial from agro-industrial by-products against $S$. Typhimurium. LWT-Food Science and Technology 77: 126-133.

Sanz-Puig M, Lázaro E, Armero C, Alvares D, Martínez A and Rodrigo D (2017b) S. Typhimurium virulence changes caused by exposure to different non-thermal preservation treatments using C. elegans. International Journal of Food Microbiology 4(262): 49-54.

Sanz-Puig M, Velázquez-Moreira A, Torres C, Guerrero-Beltrán JA, Cunha LM, Martinez A and Rodrigo D (2018) Resistance changes in Salmonella enterica serovar Typhimurium treated by High Hydrostatic Pressure and Pulsed Electric Fields and assessment of virulence changes by using Caenorhabditis elegans as a test organism. Innovative Food Science and Emerging Technologies 51: 51-56.

Schroeder M, Brooks BD and Brooks AE (2017) The Complex Relationship between Virulence and Antibiotic Resistance. Genes (Basel) 8(1) 39: 1-23.

Silva A, Genoves S, Martorell P, Zanini SF, Rodrigo D and Martinez A (2015) Sublethal injury and virulence changes in Listeria monocytogenes and Listeria innocua treated with antimicrobials carvacrol and citral. Food Microbiology 50: 5-11.

Sudhaus N, Pina-Pérez MC, Martínez A and Klein G. (2012) Inactivation kinetics of spores of Bacillus cereus strains treated by a peracetic acid-based disinfectant at different concentrations and temperatures. Foodborne Pathogens and Diseases 9(5): 442-452.

Tiwari BK, Valdramidis VP, O'Donnell CP, Muthukumarappan K, Bourke P and Cullen PJ (2009) Application of natural antimicrobials for food preservation. Journal of Agricultural and Food Chemistry 57: 5987-6000.

Tiwari R and Tiwari G (2011) Use of antibiotics: from preceding to contemporary. Scholar' $s$ Research Journal 1: 59-68.

Ultee A, Kets EP, Alberda M, Hoekstra FA and Smid EJ (2000) Adaptation of the food-borne pathogen Bacillus cereus to carvacrol. Archives in Microbiology 1744: 233-238.

Viuda-Martos M, Ruiz-Navajas Y, Fernandez-Lopez J and Perez-Alvarez J (2007) Antibacterial activity of lemon (Citrus lemon L.), mandarin (Citrus reticulata L.), grapefruit (Citrus paradisi L.) and orange (Citrus sinensis L.) essential oils. Journal of Food Safety 28: 567-576.

Wang E and Wink M (2016) Chlorophyll enhances oxidative stress tolerance in Caenorhabditis elegans and extends its lifespan. Peer Journal 4: 1-17

WHO (2017) WHO priority pathogens list for R\&D of new antibiotics. http://www.who.int/news-room/detail/27-02-2017-who-publishes-list-of-bacteria-for-whichnew-antibiotics-are-urgently-needed 
521 Zanini S, Silva A, Rosenthal A, Rodrigo D and Martinez A (2014) Influence of the Treatment of 522 Listeria monocytogenes and Salmonella enterica Serovar Typhimurium with citral on the 523 efficacy of various antibiotics. Foodborne Pathogens and Diseases 11(4): 265-271.

524

525

526

527

528

529

530

531

532

533

534

535

536

537

538

539

540

541

542

543 
544 TABLE 1. Percentiles for $C$. elegans when fed with the different $S$. Typhimurium sub 545 populations.

\begin{tabular}{c|c|c|c}
\hline & $\begin{array}{c}\text { Untreated } \\
\text { S. Typhimurium }\end{array}$ & $\begin{array}{c}\text { S. Typhimurium } \\
\text { treated once }\end{array}$ & $\begin{array}{c}\text { S. Typhimurium } \\
\text { treated three times }\end{array}$ \\
\hline Percentile & Time (days) & Time (days) & Time (days) \\
\hline 75.0 & 2.4 & 3.9 & 3.3 \\
50.0 & 5.3 & 8.5 & 8.2 \\
25.0 & 10.2 & 13.9 & 13.4 \\
\hline
\end{tabular}

546

547

548

549

550

551

552

553

554

555

556

557

558

559 


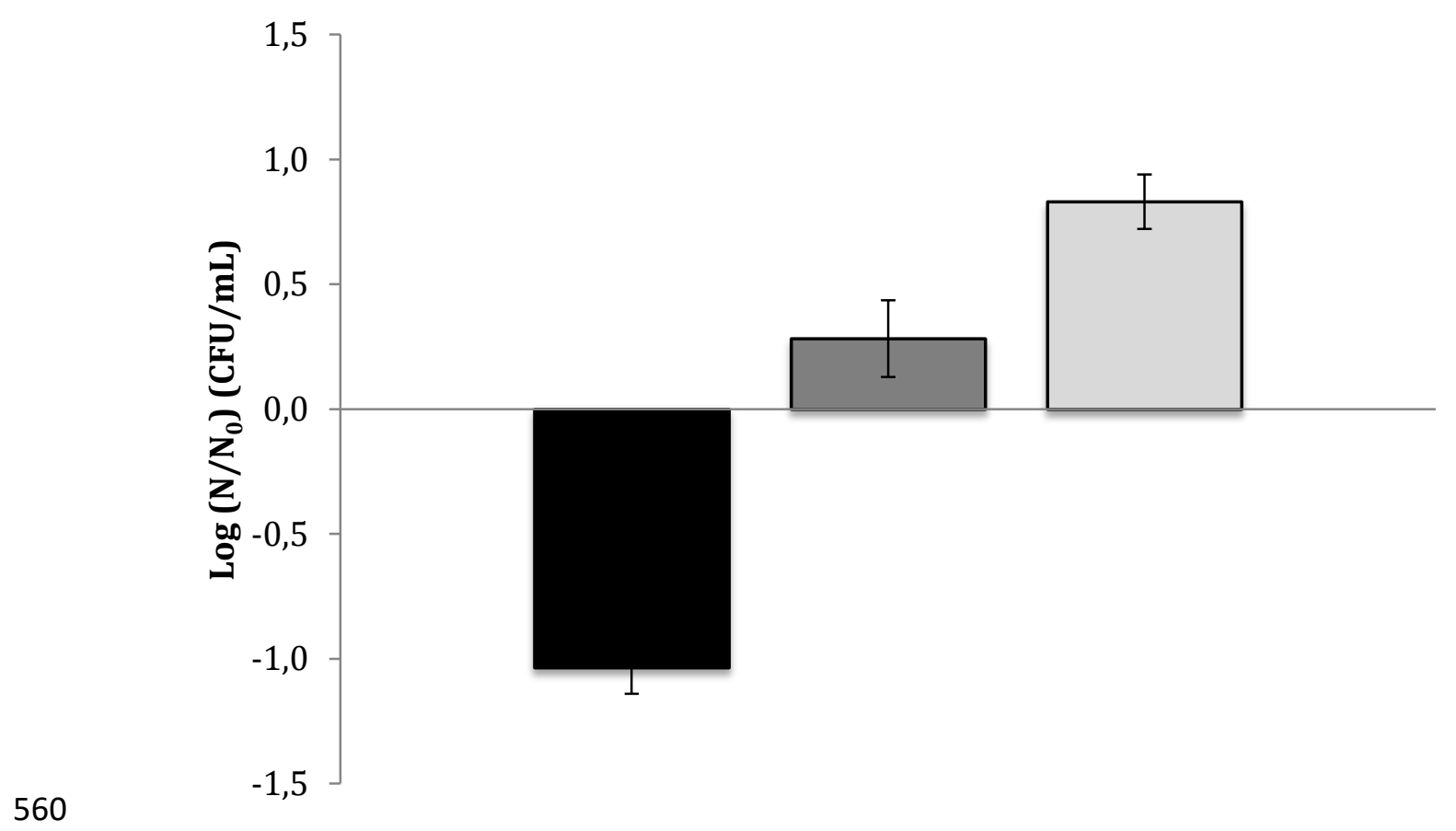

561 FIGURE 1. Evolution of $S$. Typhimurium resistance when subjected to repeated antimicrobial 562 treatments with $5 \%$ cauliflower by-product infusion (Initial bacterial count $10^{7} \mathrm{CFU} / \mathrm{mL}$ ).

563

Treated once, Treated two times, Treated three times

564

565 


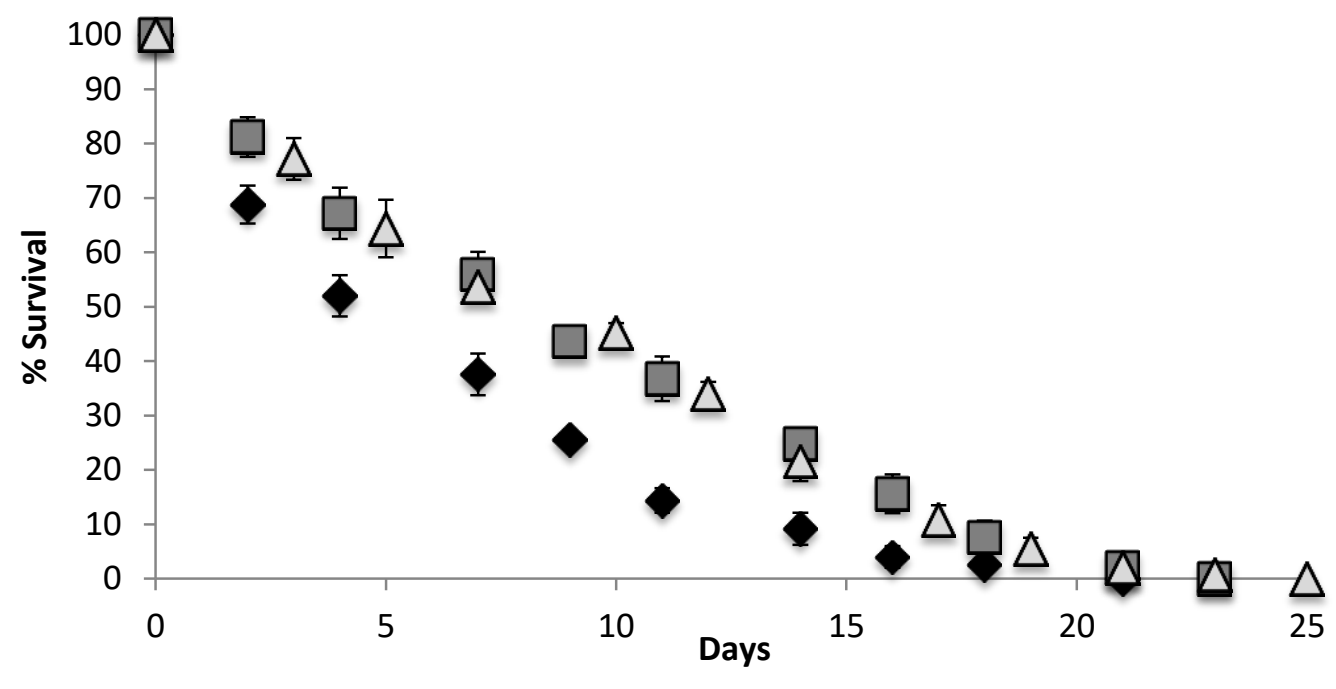

$\diamond$ S. Typhimurium $\square$ S. Typhimurium $1 \quad \Delta S$. Typhimurium 3

FIGURE 2. Survival function of $C$. elegans when fed with untreated $S$. Typhimurium and $S$.

572 Typhimurium treated once and three times with cauliflower by-product extract.

$573 \triangle$ Untreated, $\square$ Treated once, $\triangle$ Treated three times. 


\section{Estimated Hazard Function}

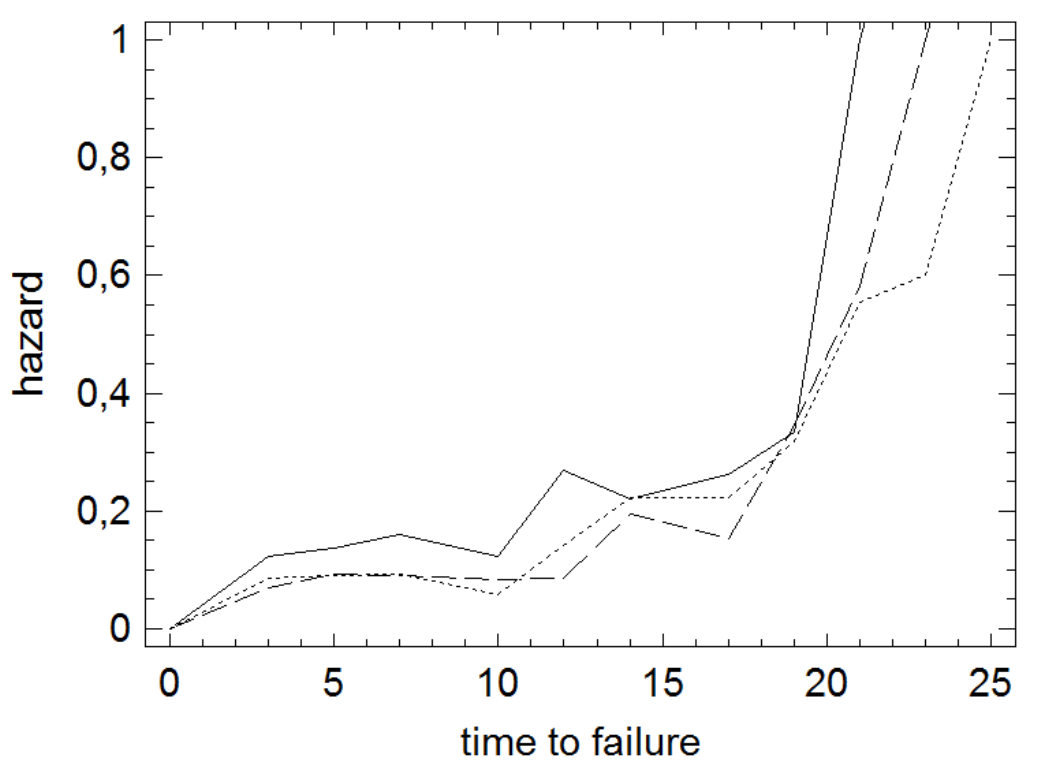

585

FIGURE 3. Hazard function of $C$. elegans when fed with untreated $S$. Typhimurium and $S$. Typhimurium treated once and three times with cauliflower by-product extract. 
Box-and-Whisker Plot

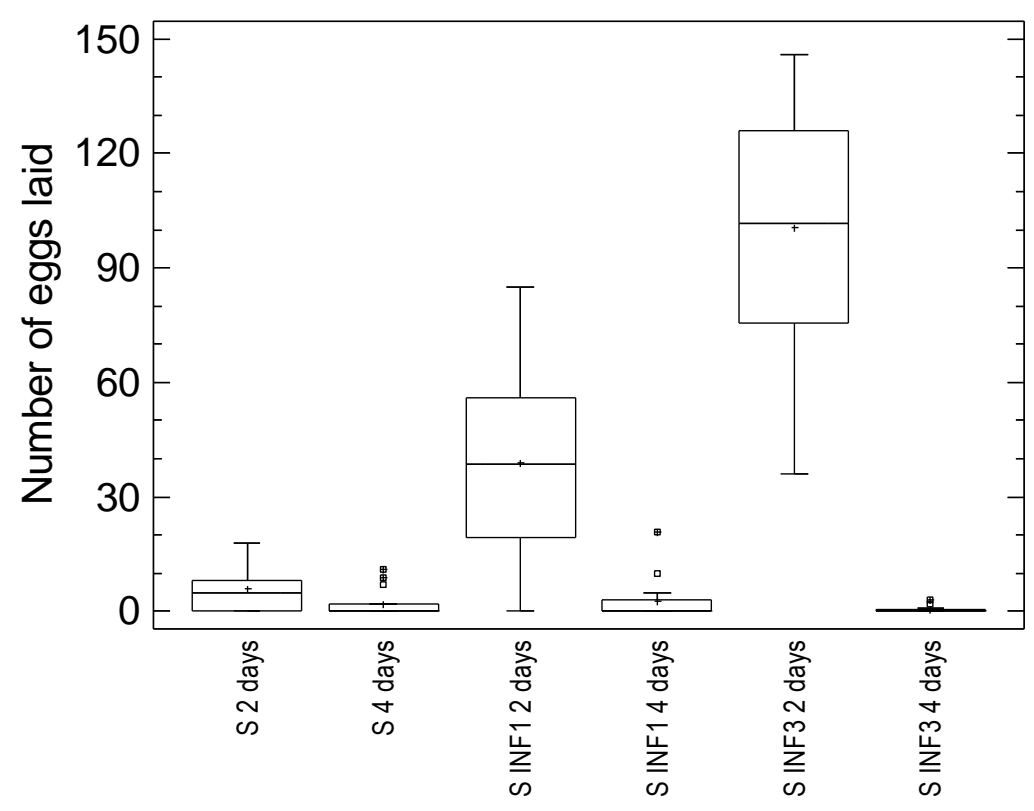

614

615 FIGURE 4. Eggs laid during first two time intervals by $C$. elegans fed with different $S$.

616 Typhimurium populations.

617 S= Salmonella without treatment

618 SINFE 1= Salmonella treated once

619 SINFE 3= Salmonella treated three times

6202 days= Eggs laid at day 2

6214 days= Eggs laid at day 4

622

623

624 